05

\title{
MULTI-SCALE INTERLINKAGES FOR TRANSFORMATION TO SUSTAINABILITY
}

\section{Mahmood Yekeh Yazdandoost}

Advisor, Biodiversity \& Wildlife Bureau, Natural Environment \& Department of Environment, Tehran, Iran Email: yazdandoost3000@gmail.com

How to cite this paper:

Yazdandoost, Mahmood Yekeh (2021) Multi-Scale Interlinkages for Transformation to Sustainability, Journal of Global Resources, Vol. 07 (02)

DOI:

10.46587/JGR.2021.v07i02.005

Received: 21 March 2021

Reviewed: 10 April 2021

Revised: 27 May 2021

Final Accepted: 30 May 2021

\begin{abstract}
For balancing the 3 pillars of sustainable development and providing policy actions, SDGs have been considered as unified goals and interlinked targets into nexus. Since the multi-scale interlinkages promote policy coherence for proper transformation to sustainability, the nexus looked into interdependencies and interconnections among components which build up our environment, including nature's contributions to people and a good quality of life. The paper identified challenges and opportunities and assessed the possible synergies among the diverse aspects of the nexus.
\end{abstract}

Keywords: Sustainable Development, Policy Action, Nexus, Multi-Scale Interlinkages.

Freely available Online www.isdesr.org 


\section{Introduction}

The global sustainability challenges are closely interlinked. Nexus approach to integrate various components of social-ecological systems along with economical dimension is necessary to overcome the challenges towards sustainability. The nexus framework through system integration recognizes the interdependencies among components and with connecting them, addressing them together. It persuades policymakers to practice on the reciprocal actions and influence between single SDGs in arrangement to receive co-advantage and diminish the venture of trade-offs (Boas et al. 2016; Liu et al. 2018). The SDGs Nexus refers to the interconnectivity, interdependencies and linkages among SDGs goals and targets. The approach is based on the development of the key interactions between human and natural systems and pursues through integrated holistic approaches across targets interconnectivity. The purpose of developing nexus approach is to promote system efficiencies and transforming planning practices though space and time by mainstreaming the natural and human resource management processes. The approach is based on the untapped inter-dependencies between the components of the system.

However, interactions among the SDGs targets indicate some are bolstering and interdependent, showing capacity to develop synergies, some are independent or deconnected, and others impose limitations or constraints, showing trade-offs. The ratings of synergy, independent and trade-offs among the SDGs targets depend upon the geographical situation, resources availability and the developmental phase of the accepted policy action (Vehmas, J. et al. 2007). Systems integration has been applied successfully to multiple dimensions of natural resources management, like; Integrated Coastal Zone Management (Portman M. E. et al.), Marine Spatial Planning (White C. et al.) and Ecosystem-Based Management (Szaro R. C. et al.).

In order to provide viable policy options to the Sustainable Development Goals (SDGs), this article was prepared in response to the interlinkages among biodiversity (SDGs 14 \& 15), no poverty (SDG 1), zero hunger (SDG 2), good health (SDG 3), water (SDG 6), energy (SDG 7), climate action (SDG 13), peace and partnerships (SDGs 16 \& 17) as coherent transformations to sustainability. Strong interlinkages exist among the Sustainable Development Goals (SDGs), that's why the SDGs are regarded as integrated and indivisible goals for sustainability. With increasing global population, global challenges are profoundly interconnected (Liu, J. et al.). Global population is expected to reside by two-thirds in urban areas by 2050 (Ritchie, H. \& Roser, M. 2018). In addition, the increased urbanisation would lead to more ecosystem degradation in bad managed development. Since livelihood is the key to sustainability, livelihood security would be a big challenge to the governance system. The livelihood security would create community cohesiveness and provide a means for poverty reduction and security. Environmental livelihood security (ELS) considers the challenges of sustaining global food, freshwater and energy security and identifying sustainable solutions to future development processes (Biggs, E.M. et al. 2014).

Currently the diverse ecosystems of our planet are under severe pressures by human activities and become unsustainable to support global populations (Allsopp, M. et al. 2009; Steffen, W. et al. 2015; Nash, K.L. et al. 2017; IPBES, 2019; GEO-6, 2019). Ecosystem degradation undermines ecosystem productivity and well-being. Though the Zoonotic diseases are significant threats to humans, the nature consider as the source of natural medicines as by today 4 billion people rely on natural medicines for their health care and wellbeing. As a result, through inter-relatedness and interdependencies of ecosystems and humans, the functioning, productivity and management of this complex social environmental 
system is taken into consideration. SDGs 1, 2, 3, 6, 7and 13 depends on SDGs 14 and 15 which impact SDGs 16 and 17 globally. Also, nexus approaches interact across multi sectors and organizations and are at the centre of the SDGs.

Biodiversity, food, water and energy nexus are essential for eradicating poverty, good health, climate action, peace and partnerships. Therefore, the environmental resources' interconnections and interdependencies are fundamental solution to sustainable development (Hoff, H. 2011). For nature-based solutions, nexus is highly effective in managing resources and supporting human environment (Rasul, G. and Sharma, B. 2016; Krchnak, K.M. et al. 2011; IUCN, 2020). The impacts of climate change already have been seen in various sectors like; agriculture, forestry, livestock, health and livelihood. Moreover, climate change impact biodiversity and the biodiversity consider being an important component of nexus. Climate, water, energy and biodiversity systems are highly connected and in diverse ecological system biodiversity provide various ecosystem goods and services. Biodiversity is a crucial component for ecosystem functionality and operability (Krchnak, K.M. et al. 2011). A safe and sound ecosystem provides clean and adequate water to grow crops and produce energy. Climate, water and biodiversity are firmly dependent upon each other, and biodiversity connects and energizes the system. Biodiversity also underlie water, energy, climate and the food security. Any disturbance on any of these components would jeopardize the availability of others.

Nexus approach accelerates sustainability pathways by identifying synergistic effects and co-benefits, and enhancing resource use efficiency (Biswas, A. K. 2008), pollution reduction ( $\mathrm{Li}, \mathrm{X}$. et al. 2012 and Amon, $\mathrm{R}$. et al. 2015) and providing linked and consistent policy to the system (UN, 2016). Nexus investigation main objective is to uncover nexus cobenefits (Bartos, M. D. \& Chester, M. V. 2014) and synergies (Rasul, G. 2014) for resource use and production optimization and security (Water Security, 2012; De Laurentiis, V. et al. 2016; Mukuve, F. M. \& Fenner, R. A. 2015; Tilman, D. \& Clark, M. 2014; Hussey, K. \& Pittock, J. 2012). Hence, sustainable management of resources provides means for sustainable development.

The Social dimension of sustainable development embraces significance of equity, equality, empowerment, participation and cultural recognition. Therefore, social sustainability creates nexus to alleviate poverty, reduce hunger, promote health, conserve biodiversity and develop stable partnerships for peace and stability. An integrated ecosystem with high carrying capacity provides productive and resilient condition to support life. The current rate of biodiversity decline is enormously high. One of the reasons is the climate change. Climate change destabilizes the environment and reduces the resiliency of the natural conditions. Also, shifts the boundaries of global biomes and creates mass migration for animals. We can't plan health without considering biodiversity, climate, water, energy, poverty, hunger, and peace and partnership issues. These factors are highly interlinked. Anyone of them needs the rest of it to be considered in nexus. Nexus-based approaches would incorporate reciprocal actions among sectors and stakeholders to promote collaboration and speed up the transformation towards sustainable development. As a result, instead of looking at individual components of sustainability in isolation, through nexus approach the functionality, productivity and management of the complex system would be considered. This approach would assist the consistent development of the sustainability principles of actions. With above explanation, the objective of this paper is to identify how nexus approach promotes policy actions for sustainable development in Iran. 


\section{Method}

With the focus on higher order interactions, the interlinkages between the transformative change and the nexus assessment among biodiversity, no poverty, zero hunger, good health, water, energy, climate action, and the systems pertaining to peace and partnerships has been taken into account. The nexus assessment extract information from various knowledge systems to explore the interconnection between ecosystem and ecosystem services to society for the good quality of life and well-being. The methodology considered here, comprises the collection of integrated cross-sectoral information for various ecosystem connectivity to promote systemic approach towards environmental policy actions.

\section{Results and Discussion}

The result indicates, the policy and structural options to accelerate transformative changes in facilitating the transition to a sustainable future within the context of the nexus issues needs the potential of cross-sectoral planning and management, and innovative policy interventions. Realizing the nexus among targets of SDGs would assist the integration of sectoral programs and cross-sectoral coherence policy to detect synergies. We need to institutionalize nexus to achieve sustainable development goals (Keairns, D.L. et al. 2016). Nexus approach is a system thinking approach that considers every possible components of the system for balancing the functionality of the system. Thus, monitoring the nexus across sectors is a key challenge to sustainable development achievement (Smajgl, A. et al. 2016). Through policy coherence and integrated governance system should create opportunities and benefit all.

In healthy environment with sufficient water availability, the biodiversity in agriculture produces enough food, year-round for the growing human population and bringing health to society. Nature-based solutions through nexus approach are also effective in adaptation to climate change (Rasul, G.and Sharma, B. 2016). The Nexus approach also would maintain ecosystems well-being by delivering ecosystems services more efficiently and enhancing resiliency to the environment. Generally, the expense of nexus scheme is much higher than those traditional silo approaches. The Nexus scheme not only requires expertise and experience in all relevant sectors but also coordination among experts in different sectors, which brings about additional charges. Developing nexus frameworks is the base for the understanding of multiple relationships and synergy among sectors to provide further thorough analysis to achieve policy objectives. By doing this, the nexus would become a system of interconnected components that sustain life on the planet earth.

The key to the nexus approach is to recognize the points of interactions among the resource systems for the exchange of the information and to identify, how the output from one component would become the input for other linked components. Because of these interactions from the interdependencies and interconnections among components of the system, the policy-makers and decision makers from multi sectors and scales would tackle the complex challenges in the nexus approach (Leck, H.et al. 2015). Although, the SDGs nexus presents opportunities for policy makers, investors and public at large to address the interdependent global security concerns; the lack of appropriate data and knowledge gaps to apply for the nexus-based solutions to global problem is a great global challenge. When we convert land for the expansion of urban areas, the ecosystems connectivity gets immensely transformed, impacting hydrological cycles and precipitation, ecosystem productivity and local climatic conditions (Alberti, M. 2005). In this way, landscape disturbance creates great challenges for the delivering ecosystems goods and services to a growing population. Also, we should be concerned about the climate change impacts, natural ecosystem disruption and 
multi challenges in our urban areas system that threaten our safety and security for now and future.

For acquiring global resource needs and environmental sustainability, the nexus framework should expand towards terrestrial and freshwater systems as well as marine and coastal systems. As a result, nexus approach would adapt the socio-economic, health, environment and development-oriented targets within and across the SDGs (Giupponi, C. \& Gain, A. K. 2016). Also, economic activities' impacts on sustainability issues should be concerned in an integrated way, that enhances co-advantages and reduces trade-offs (Allen et al. 2019). Although countries supportively admit the SDGs, there are several gaps in their responsibilities with the SDGs to avoid environmental degradation (van Zanten JA. \& van Tulder R. 2018). The SDGs concerned with the environment usually suffers from economic activities. Industries should improve their environmental footprint by contributing positively to the ecological systems and reducing negative externalities.

Through Circular Economy we can balance our economic development with increasing efficient use of natural resources through recycling, sustainable harvesting and protecting ecosystem connectivity. The Circular Economy aims in reducing energy consumption, reducing pollutants emission and increasing cleaner production in industries, agricultural fields and urban areas (UNEP, 2013). For the long-term sustainability to development, we must understand that our natural resources are finite. For this regard, insufficient initiatives across sectors led to incoherence policies for sustainable development. As a result, the sustainability challenges and turbulence we are confronting today and the way multiple economic activities contribute to them, definitely directing us to synthesize nexus-based approach to earn comprehensive solutions.

Besides the economic relations, educational and cultural relationships tie the nation's together (Kaplan, B. 1993; Moore, M. 1993). Hence, communication would pave the current global development pattern and significance for sustainable development. With the current global relations, sustainable development considers the center of global policy agenda for development. It provides a mechanism for promoting living conditions, ecosystem well-being and a safe habitable planet for all the creatures. As a result, the nexus-based approach would give better clue, while we intend to provide stronger evidence-based solution to decisionmakers, to ensure sustainable maintenance of ecological system with all its relevant components, including the health and communication.

\section{Recommendation}

- The interlinking health system with no poverty, zero hunger, water, energy, climate action and biodiversity nexus are essential to achieve a healthy resilient society.

- Nexus approach through accelerating integrated planning and management can reduce global challenges.

- Through nexus framework enhance and accelerate coordination, cooperation and policy cohesion at national level.

- Promote resilient environment through innovation and sustainable production.

- Promote environmental integrity through biodiversity conservation and climate change mitigation.

- Promote solidarity and societal cohesiveness for sustainability.

- Advocate development strategies that protect our environment and promote people's health. 


\section{Conclusion}

Nowadays, the sustainability issues from public are receiving major attention. It is highly recognized that human activities create devastating ecological footprint with irreversible loss of species. Threat to biodiversity, climate and ecosystem goods and services is compounding major challenges, which needs through integrated approach to get resolved. The dynamic connection among biodiversity, food, water and energy ensures eradicating poverty, good health, peace and partnerships and resiliency to climate change. Higher synergy values occur, when the programs and policies embedded into cross-sectoral targets. Achieving the SDGs requires good governance to manage the synergies among targets. The nexus approach gains advantages from the multi-sector and multi-scale perspectives to solve sustainability challenges. Nexus framework would bring inter and intra sectoral cooperation to promote cohesive long-term planning and helps policy makers to efficiently use the natural and human resources through good governance practices.

The integrated-nexus-based-governance for the SDGs will benefit economic activities and social cohesiveness without harming the environment. Industries should make valuable contributions towards sustainable development by ensuring that positive interactions appear bolder and negative interactions gradually disappear from the surface of earth. The global transformation to sustainability requires assurance alignment among the three pillars of sustainable development in terms of the regenerative capacity of the planet's life-supporting ecosystems. This dynamic equilibrium may create sustainability to economy, society and environment in a true sense. Sustainable development should not be considered in isolation. Integrated efforts through nexus approach would pave the sustainability goals more effectively. Hence, achieving sustainable development is not an easy task. It highly relies on ecosystem integrity and biodiversity conservation, green production and consumption pattern, health and moral well-being, natural resources management and renewable energy production, policy coherence and community participation. Participation with reference to policy approach, involves social groups in decision-making processes. This approach enhances social cohesion and social sustainability.

The sustainability issues are not inseparable and indivisible issues, but the global crisis of social-economical-ecological systems require mainstreaming approach and integrated response. Overcoming knowledge gaps by integrating knowledge production provide holistic response to socio-economic and environmental crisis. However, the Nexus approach requires collaborative effort and coordination attempt across sectors, scales and organizations for transparent decision-making. Since, the SDGs are considered to be cross-cutting and implemented together; it is very hard to imagine solution for any issues of sustainability in isolation. As a result, the nexus-based approach not only horizontally should have capability to be replicated in other geographic areas but also vertically to get institutionalized at different capacity building levels. Thus, synergies across sectors would create coherent policies to boost opportunities for further adaptive development.

In addition, our environmental planning and management approach still happening along sectoral lines, that is in silos condition, rather than as an integrated and unified processes, unable to utilize the cross sectoral synergistic capacity to mainstream resource management. Thus, we should allow the ecosystems connectivity, which deliver essential ecosystem goods and services necessary to support the survival of future generations to continue its function. Exploitation should be within ecosystem carrying capacities. That's how the development would be meaningful and sustainable. 
Acknowledgement: All the scientific literatures released by academia, UN and other agencies including Department of Environment that have been used in this research article are highly appreciated.

\section{References}

1. Alberti, M. (2005). The effects of urban patterns on ecosystem function. Intern. Regional Science Review, 28(2), 168-192.

2. Allen C, et al. (2019). Prioritizing SDG targets. Sust Sci. 14(2):421-438.

3. Allsopp, M. et al. (2009). State of the World's Oceans; Springer, ISBN 978-1-4020-9115-5.

4. Amon, R. et al. (2015). Waste heat and water recovery opportunities in California tomato paste processing. Appl. Thermal Eng. 78, 525-532.

5. Bartos, M. D. \& Chester, M. V. (2014). The conservation nexus: valuing interdependent water and energy savings in Arizona. Env. Sci. Technol. 48, 2139-2149.

6. Biggs, E.M. et al. (2014). A nexus-livelihoods approach for spatially assessing change.

7. Biswas, A. K (2008). Integrated water resources management, Int. J. Water Resour. Dev. 24, 5-22.

8. Boas I, et al. (2016). Cross-sectoral strategies in global sustainability governance. Int Environ Agreements. 16(3):449-464.

9. De Laurentiis, V. et al. (2016). Overcoming food security challenges within an energy/water/food nexus (EWFN) approach. Sustainability 8, 95.

10. GEO-6. (2019). Healthy Planet, Healthy People. ISBN 978-1-108-62714-6.

11. Giupponi, C. \& Gain, A. K. (2016). Integrated spatial assessment of the water, energy and food dimensions of the sustainable development goals. Region. Env. Change 17, 1881-1893.

12. Hoff, H. (2011). Understanding the nexus. Stockholm, Sweden.

13. Hussey, K. \& Pittock, J. (2012). The energy-water nexus: managing the links between energy and water for a sustainable future. Ecol. Soc. 17, 31.

14. IPBES (2019). Bonn, Germany.

15. IUCN (2020). Global Standard for Nature-Based Solutions, Switzerland.

16. Kaplan, B. (1993). Social change in the capitalist world.

17. Keairns, D.L. et al. (2016). The Energy, Water, Food Nexus. Biomol. Eng. 7, 239-262.

18. Leck, H.et al. (2015). Tracing the water-energy-food Nexus. Geogr. Compass, 9, 445-460.

19. Li, X. et al. (2012). Energy-water nexus of wind power in China. Energy Pol. 45, 440-448.

20. Liu, J. et al. (2015). Systems integration for global sustainability. Science 347.

21. Liu J. et al. (2018). Nexus approaches to global sustainable development. Nature Sust. 1 (9):466-476.

22. Moore, M. (1993). Globalization and Social Change.

23. Mukuve, F. M. \& Fenner, R. A. (2015). Scale variability of water, land, and energy resource interactions and their influence on the food system in Uganda. Sust. Prod. Consum. 2, 79-95.

24. Nash, K.L. et al. (2017). Planetary boundaries for a blue planet. Nat. Ecol. Evol. 1,1625.

25. Portman M. E. et al. (2012). Improving integration for integrated coastal zone management: Total Environ. 439,194-201.

26. Rasul, G. (2014). Food, water, and energy security in South Asia: a nexus perspective from the Hindu Kush Himalayan region. Env. Sci. Pol. 39, 35-48.

27. Rasul, G.\& Sharma, B. (2016). The nexus approach to water, energy, food security. 6, 682-702.

28. Ritchie, H., \& Roser, M. (2018). Urbanization: Our World data.

29. Smajgl, A. et al. (2016). The water-food-energy Nexus. J. Hydrol., 533-540.

30. Steffen, W. et al. (2015). Planetary boundaries: Guiding human development on a changing planet. Science, 347, 1259855.

31. Szaro R. C. et al. (1998). The emergence of ecosystem management as a tool for meeting people's needs and sustaining ecosystems. Landsc. Urban Plan. 40, 1-7.

32. Tilman, D. \& Clark, M. (2014). Global diets link environmental sustainability and human health. Nature $515,518-522$.

33. UNEP (2013). City-Level Decoupling: Urban resource flows and the governance of infrastructure transitions.

34. UN (2016). Development and globalization.

35. Van Zanten JA. \& van Tulder R. (2018). Multinational enterprises and the sustainable development goals. J Int Bus Policy. 1 (3-4):208-233.

36. Vehmas, J. et al. (2007). Linking analyses and environmental Kuznets curves for aggregated material flows in the EU. J. Clean Prod. 15, 1662-1673.

37. Water Security: the Water-Food-Energy-Climate Nexus (World Economic Forum Water Initiative (2012). Island Press, Washington DC.

38. White C. et al. (2012). Ecosystem service tradeoff analysis reveals the value of marine spatial planning for multiple oceans uses. Proc. Natl. Acad. Sci. U.S.A. 109, 4696-4701. 